\title{
Unresectable Rectal Adenocarcinoma
}

National Cancer Institute

\section{Source}

National Cancer Institute. Unresectable Rectal Adenocarcinoma. NCI Thesaurus. Code C162117.

A rectal adenocarcinoma that is not amenable to surgical resection. 